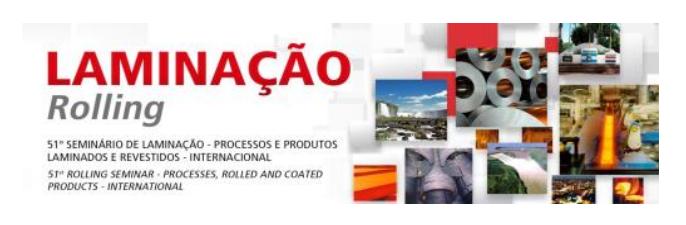

\title{
ROLLING YESTERDAY, TODAY AND THE CHALLENGE FOR TOMORROW*
}

Karl Berger ${ }^{1}$

Franz Holy ${ }^{2}$

\begin{abstract}
The paper gives a comprehensive overview of the historical development of various metal rolling technologies and also describes the influence to industrial and socioeconomic developments. The rolling of steel, in particular of rails, beams, rebar, strip and plate has enabled the large scale transport and travel, the building of bridges and buildings, the manufacturing of ships and cars. All this has changed the face of the world significantly. Further the paper approaches technological highlights in the design, manufacturing, drive and control of modern mills and the various types developed to create industrial economic units for the different markets and customers' requirements. An outlook of future challenges is as well discussed in the paper. Various solution approaches for the rolling technologies, from continuous improvement of existing plants to more radical new concepts like endless rolling, near net-shape casting and rolling are approached. A positive conclusion is drawn that rolling technologies will remain a valuable area for engineers with scientific and economic challenges, but also a clear vision for positive contribution to further industrial and social development.
\end{abstract}

Keywords: Rolling; Highlights; History; Challenge for tomorrow.

International Business Consultant (KB.IC).

CTO EVRAZ International Business Division.

* Technical contribution to the 51st Rolling Seminar - Processes, Rolled and Coated Products, October $28^{\text {th }}$ to $31^{\text {st }}$, 2014, Foz do Iguaçu, PR, Brazil. 


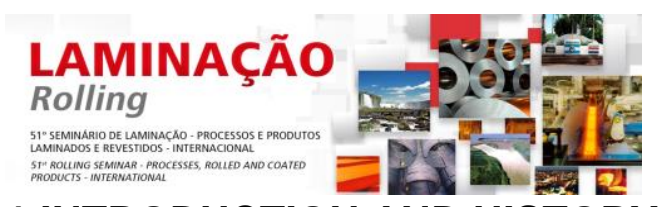 \\ 1 INTRODUCTION AND HISTORY}

There is a Ribbon of Fire running around the World It runs Day and Night It runs out of the Past and into the Future And it feeds the World Few among millions know this We are the Few who tend the Ribbon of Fire Long may it serve us All

(Notice seen on an office wall at Inland Steel's Indiana Harbor 80" HSM in 1987. Author unknown)

\subsection{The Hot Strip Mill}

More worrying than the equivocations over definitions is the failure of some textbooks to capture the relevance of the WSM (Wide Strip Mill) itself. In one of the standard textbooks on the history of technology, appeared in 1978, the WSM is dealt with in a short paragraph, as little more than an afterthought after a considerable amount of pages devoted to improvements in blast furnace and steel refining. The unique nature and the unprecedented consequences of WSMs are thus totally lost. David Landes in his path-breaking survey of technological innovation in Western Europe was more generous. He argued that "the wide strip mill was the most important single advance in iron and steel technology in the interwar period" and went on to discuss the introduction of a WSM at Ebbw Vale in 1938, against the resistance of the large majority of the steel trade. Even Landes, however, has little to say about the large-scale introduction of Generation I WSMs across Western Europe after 1945. Nor he does not track the momentum of technological innovations descending from the wide strip mills, to include not just cold reduction, but also coating and finishing continuous throughput technology. Only very recently has research on the process of post-war Americanization in Western Europe, uncovered the significance of wide strip mills in bringing about a radical change not just in production methods, but also in management, industrial relations, company strategy and performance.

In the American literature tributes to the WSM are more generous. In his multivolume study of the American iron and steel industry, Hogan records "...the continuous strip mill was one of the greatest advances in steel making since the development of the open hearth process".

Many authors emphasize the crucial enabling role of WSMs for the automobile industry. In 1963, Fisher in his The Epic of Steel emphatically wrote:

"...it was the automobile that led the way into the new America, which came into being in the present century. The motor vehicle evoked one of the steel industry's most important technological changes. Because of the universality of sheet steel, it has more to do than any other steel product - than any other manufacturing material - in creating the new America. Sheet steel was the magic carpet on which America rode to new adventures in living".

* Technical contribution to the 51st Rolling Seminar - Processes, Rolled and Coated Products, October 28 th to 31st, 2014, Foz do lguaçu, PR, Brazil. 


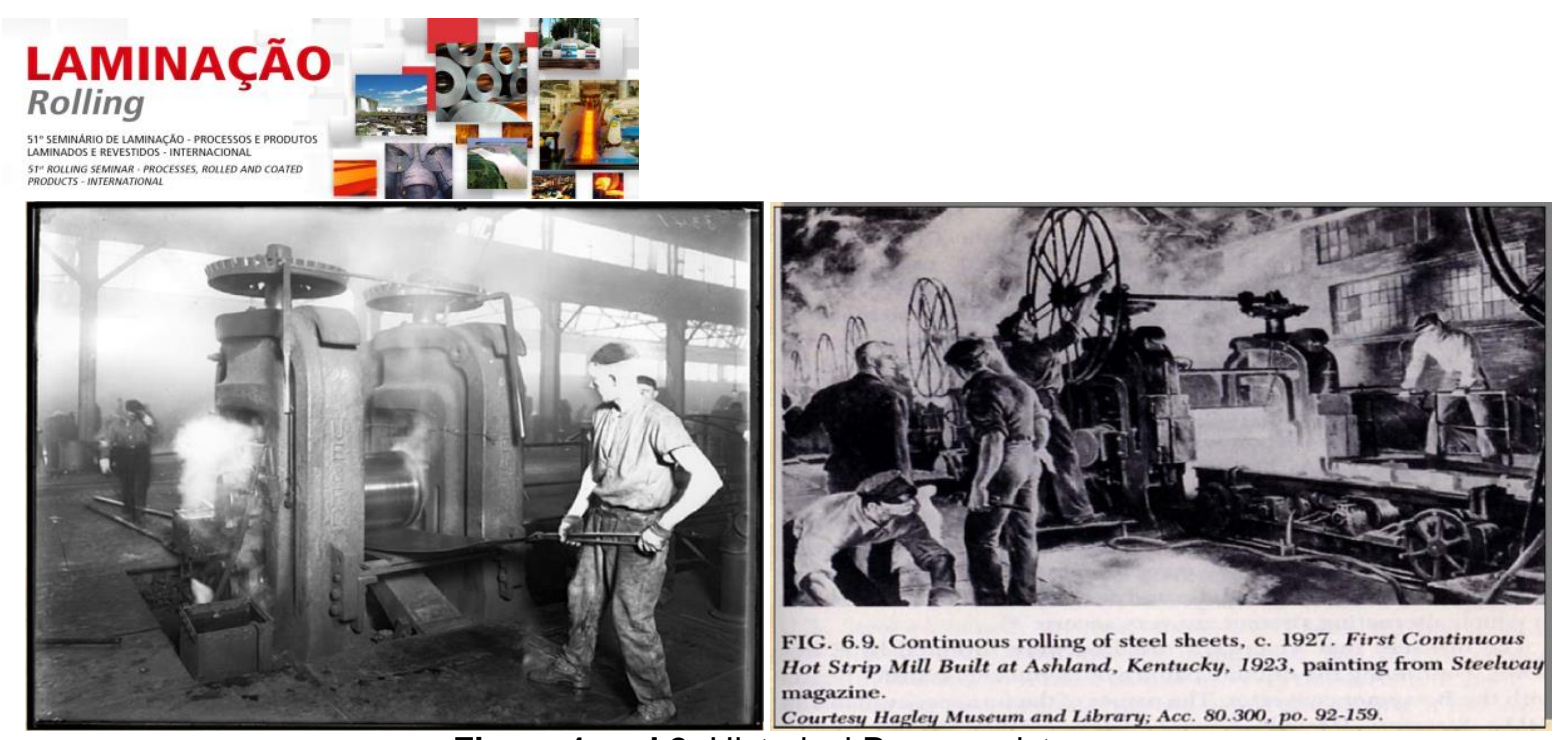

Figure 1 and 2: Historical Process pictures

The continuous WSM was a shift from a simple to a "complex" technology. Steam driven hand mills were all of a piece: both the steam engine drive and the mill stands were made up of castings and simple machined moving parts. A simple brass foundry was all that was needed to supply replacement journal bearings and the complete works could be readily maintained by skilled millwrights equipped with tacit knowledge and experience. The hand mill was the product of a craft era.

In contrast, continuous WSM were complex in the sense that they drew of a range of inter-acting technologies and it was no longer possible for one person to understand all the features of the complete system of rolling. Ward-Leonard controls used to synchronize mill stands were at the frontiers of electrical engineering. United Engineering was forced to rely on roller-bearing companies for their expertise to solve the problem of friction from heavy rolling loads. The size of the new mills posed novel civil engineering challenges. In effect, the continuous WSM was a package of technologies from different sources re-combined in a novel way. This combination of breakthroughs from a range of engineering disciplines is what makes the WSM fundamentally different from earlier, narrow strip mills which shared a common layout and approach to the new technology.

The invention of the WSM came as the result of two converging lines of development: from sheet mills and from strip mills. Sheet mills rolled sheet from sheet bars. Sheets were wide and short - often they were rolled in packs. Strip mills, on the other hand, rolled billets and slabs into narrow and long strip shapes. The WSM was developed as a continuous mill, which gave a product having the dimensional characteristics of both strip and sheet, being at the same time wide and long.

An important innovation of this mill was the 4-high finishing stand. The 4-high stand allowed the work rolls to be small, supported by large diameter backup rolls - so that much greater reductions could be achieved on a single pass.

The development of the WSM was dependent on a number of interrelated technical improvements: the adoption of 4-high stands; the manufacture of bearings suitable for the demands of heavy rolling; the availability of equipment for synchronizing the motors to prevent buckling of the sheet and the existence of automatic control devices. All of these became available in the 1920s. Electrical motors and controls were essential to adjust the speed of the wide strip mill's successive stands. An important part of the credit for the technological breakthroughs belongs to the plant supplier United Engineering Company of Pittsburgh that worked closely with Columbia Steel.

* Technical contribution to the 51st Rolling Seminar - Processes, Rolled and Coated Products, October $28^{\text {th }}$ to $31^{\text {st }}, 2014$, Foz do Iguaçu, PR, Brazil. 


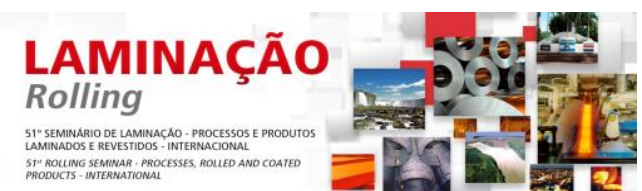 \\ 1.2 Cold Reduction and the Cold Strip Mill}

Closely tied to the introduction of WSMs was the introduction of the cold reduction mill, also called, somewhat improperly, "cold strip mill".

The gauge of the coil leaving the WSM was not exceedingly thin, particularly for the wider products. The development of continuous cold reduction allowed a further reduction of between $20 \%$ and $80 \%$ to take place, without re-heating and still maintaining the coil form. The key point about cold reduction was that it was carried out under tension, a fact that contributed in achieving the outstanding metallurgical qualities of the final product. Cold reduction proper was then followed by annealing (re-heating) and then by a second type of cold rolling called 'skin pass' or 'temper rolling'.

As a result of cold reduction, the sheet acquired a very smooth surface and it could withstand the stress of forming and drawing. Its physical properties made it very suited to be turned into tinplate, while its deep drawing qualities made it valuable to the automobile industry. Essentially, cold-rolled sheet was a new product, of a different quality from hot rolled sheet and with vast new market opportunities

The first rolling of metals was, in effect, cold rolling. Modern cold reduction mills were not developed overnight: they were the result of a period of experimentation lasting between the late 1920s and the early 1930s. The first 4-high mill for cold rolling of sheet was pioneered by Allegheny Ludlum in 1923, and the first 4-high, 4-stand tandem cold mill installed by Columbia Steel at Butler in 1926. Tandem mill operation under tension was pioneered in Pittsburgh in 1915 by the Superior Steel Company and Morris and Bailey Steel Company.

\subsection{Innovations in Coating Processes: Electrolytic Tinplating and Galvanizing}

A third batch of innovations can also be identified on the coating side. These can be seen as a direct consequence of the introduction of WSMs and cold strip mills. The first cold strip mills were expressly designed to reduce hot-rolled strip to the thinness and width necessary for tinplating. Tinplating itself, however, was still conducted in the traditional batch hot dip process. The development of a continuous tinning line technology was the result of experimentation carried out during the 1930s. The first successful electrolytic tinning line was installed by Carnegie-Illinois Co. part of US Steel at its Gary works in 1937.

The electrolytic tinning line works on a continuous basis: one coil of cold reduced strip following the other through a process of instant welding. The electrolytic tinning tank contains a tin salt in a liquid solution, and the tin is deposited as a metallic film on the steel surface by a current of electricity. Subsequently after cleansing, heating to the point of fusion of the tin, and then quenching, the strip emerges with a bright coating tin surface. As compared to the hot dipping line the new process was much faster, allowed a more even coating and considerable savings in the use of tin savings that became more substantial as the technology was improved.

Galvanized sheet experienced the same transition from the hot dip batch process to continuous throughput processing. Thaddeus Sendzimir and J.J. Bostroem in Poland developed the original patent for continuous galvanizing in 1931. Soon Sendzimir lines were installed in Europe but their impact was most profound in the US, where they fitted the requirements for rapid continuous coating throughput generated by the scale of the WSMs. Sendzimir's patent was bought and developed by Armco at its

* Technical contribution to the 51st Rolling Seminar - Processes, Rolled and Coated Products, October $28^{\text {th }}$ to $31^{\text {st }}$, 2014, Foz do Iguaçu, PR, Brazil. 


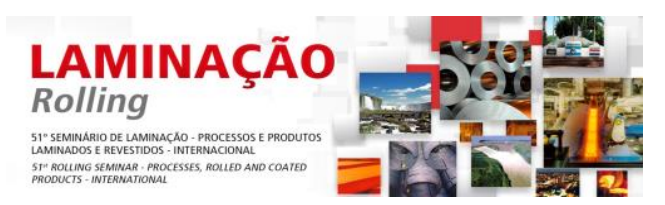

Butler plant in 1936. Soon four other installations of the same kind, known as zinc gripping lines, were installed by Armco and Inland Steel Corporation had acquired the license as well.

\section{PRESENT STATUS AND FUTURE CHALLENGES}

\subsection{New Steel Grades}

As a material, steel continues to have a high value - steel is modern. The development of steel grades has by far not yet reached its end. The market, together with its product requirements and competing materials, like for example aluminum, drive this continuous development. The following figure shows an overview of the most important steel grades in the area of hot-rolled carbon steels.

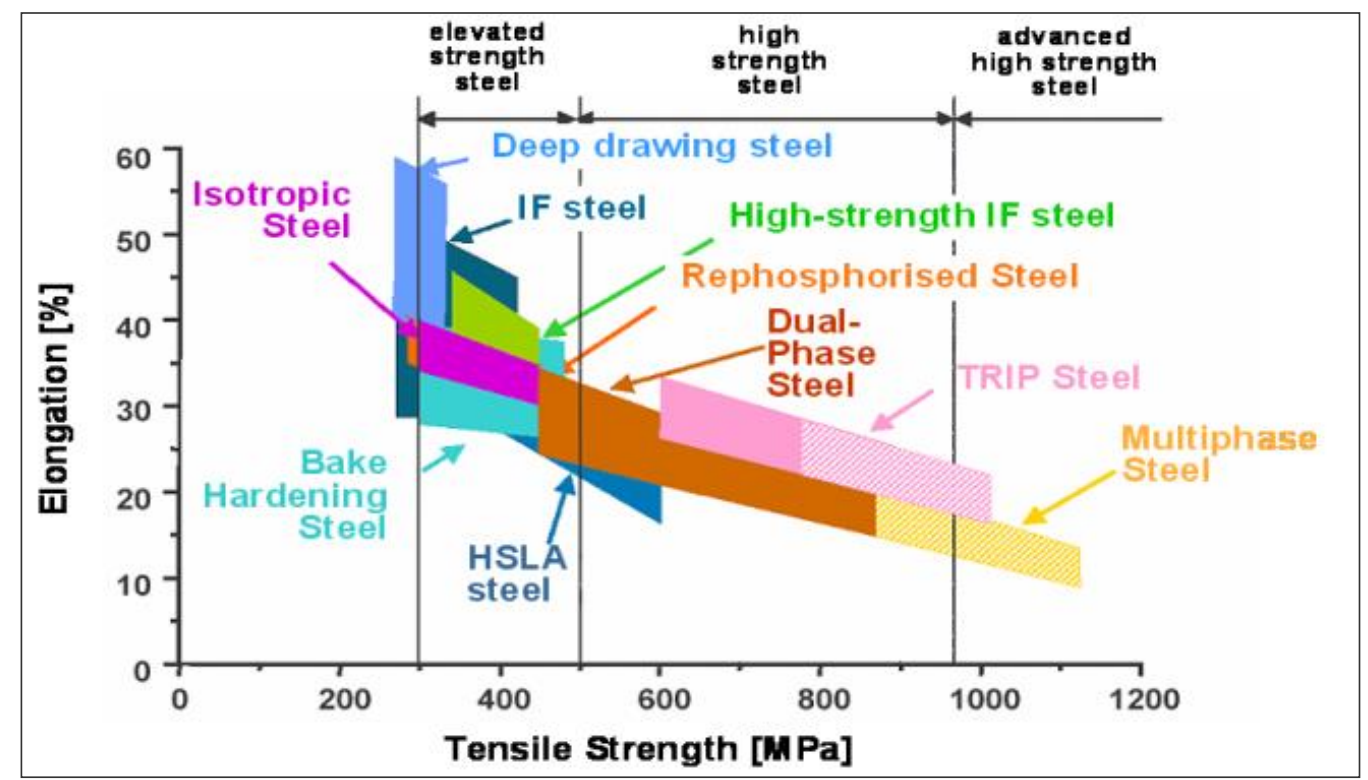

Figure 3: Steel grades in the area of hot-rolled carbon steels

Developments in the dual and multi-phase steels are worth special mention. Mill technologies accompany these developments. Sometimes, the plant builders also take part in the steel grade development, with the vision of building a "metallurgical perfect" mill.

It's also worth to say that in the last 20 years the mechanical strength of hot rolled steel has doubled from about $300 \mathrm{Mpa}$ to nowadays 600 to $700 \mathrm{Mpa}$ as an average (for car material and HSS applications - mills).

\subsection{Motors and Drives}

The motors and drive systems are the heart of any wide strip mill. Drive systems in wide strip mills have to face hard work and high demands in daily operation: constantly high loads, highly dynamic acceleration and braking operation, and mechanical and electrical shocks from heavy passes. They therefore contribute to the plant's productivity and availability figures, but they also have an important impact on maintenance costs, product quality, energy consumption and grid quality.

* Technical contribution to the 51st Rolling Seminar - Processes, Rolled and Coated Products, October $28^{\text {th }}$ to $31^{\text {st }}, 2014$, Foz do Iguaçu, PR, Brazil. 


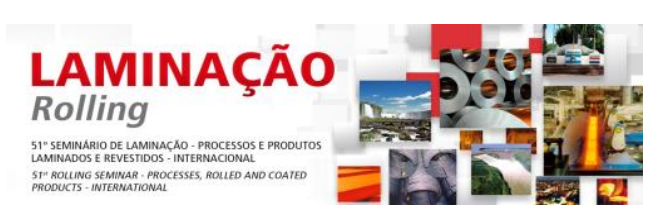

For the high dynamic requirements especially in hot strip mills, non-salient type rotor for the main drive motors have been developed, reducing the moment of inertia and the torque ripples while providing a very robust motor.

For the widest range in drive solutions, Cyclo Converters are proven and simple. For superior requirements, the newest Voltage Source Converters provide high power scalability with the newest technology. One of their advantages is that no compensation devices are required and together with the AFE (active front end) even compensation for other reactive loads can be provided.

As a result, the solution best meets the requirements of the mill stand and prevents oscillation and chatter effects right from the beginning. The selected drive solution also contributes to the construction environment as well as to the electrical boundary conditions. This applies to the design of new mills and also to mills that require a modernization of their drive systems. The conversion from DC to AC drive systems is a typical example of this.

\subsection{Cooling}

The successes of new materials are accompanied by an increase in the requirements that are placed on the classical material, steel. It is not only automotive companies that expect to gain an advantage from thinner but still very strong types of steel sheeting which makes their vehicles more efficient and more environmentally compatible; other branches of the industry can also profit from strength-relevant load-bearing structures and energy-absorbing components made of dual-phase, multiphase or high-strength steels such as TWIP and TRIP. In addition to the alloying elements, the cooling section is decisive for the properties of these steels. Precise and highly flexible control of the cooling process in the cooling section is therefore extremely important and provided by:

- Laminar cooling/turbo laminar cooling

- Quick switch header

- Intensive cooling

- Microstructure target cooling

While the laminar cooling with turbo cooling headers achieves a higher throughput and the quick switch cooling headers take care of higher accuracy in the coiling temperature, the intensive cooling is specially designed for the need of advanced steel grades.

\subsection{Intensive Cooling}

With intensive cooling, an increase in cooling capacity of approximately $200 \%$ can be achieved compared with conventional cooling. This water-pillow cooling offers a high cooling power density (up to $5 \mathrm{MW} / \mathrm{m}^{2}$ ), high cooling rate (e.g. $750^{\circ} \mathrm{C} / \mathrm{s}$ for a strip thickness of $2 \mathrm{~mm}$ ) and a large control range (cooling power density control range 1:10).

For HSLA steels and ultra-thin strip, the intensive cooling header is installed between the finishing mill and the laminar cooling section. In case of AHSS grades e.g. DP, TRIP and multi-phase steels, a 2-step cooling is preferred and a second intensive cooling header is placed between the laminar cooling section and the downcoiler.

* Technical contribution to the 51st Rolling Seminar - Processes, Rolled and Coated Products, October $28^{\text {th }}$ to $31^{\text {st }}$, 2014, Foz do Iguaçu, PR, Brazil. 


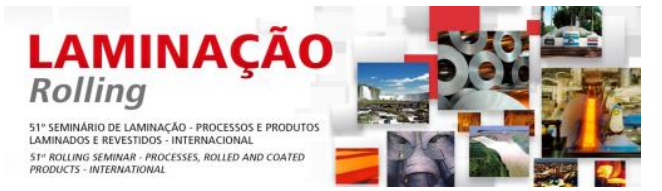 \\ 2.5 High Product Quality}

Hot-rolling mill managers face an increasing demand for high-quality products which will remain at a high level and will grow even further. Among these are the geometric properties, such as uniformity and replicability of width, thickness, profile and flatness. Surface properties are equally important, since damage to the hot-rolled strip is permanent. Suitability of strip for automobile skin production is a step that is already determined in the hot strip mill.

Only future-oriented technologies we can meet such requirements. Some examples will be presented.

\subsection{Level 1, 2, (and higher) Automation}

The nowadays advanced processes demand more and more reliable automation systems, based on exact process-data-measurement (sensors) and actuators that shall be as fail-safe as possible, and / or redundant in order to avoid any discontinuity of the process. Coupled lines, such as continuous mills, either cold or hot processing, just became possible after these reliable automation systems. The response time of such systems are in milliseconds (always have been) when we talk about fast hydraulic servo systems installed in AGCs or AWCs. Imaging that the most modern tandem mill in 1974 (Voest Alpine / Austria) had a memory capacity of only $64 \mathrm{kB}$ of the control computer and $40 \mathrm{kB}$ on the process computer, we are happy thet nowadays (exactly 40 years after) we easily play around with $60 \mathrm{~GB}$, or even terra Bytes, which is the magnitude of a million higher than 40 years ago.

To achieve the best qualities in the tight and tighter tolerances that the markets are demanding, process automation Level 2, with precise mathematical-physical set-up and control calculations with a fast and sophisticated learning is essential.

The automation provides models for all aspects of the rolling process. These include set-up calculations for tight material property control solutions (as later explained during the cooling and MSM chapter) as well as precise mill set-up calculations for speed and gap. Profile and flatness systems complement with advanced Crown Control systems.

The adaptive model for set-up calculation uses a model for friction and for - yield, and is able to consider conditions with and without rolling oil and adapting physical parameters as depicted in.

The temperature set-up for new steel grades is very important, since the material properties depend very much on the precise and flexible control of the temperature and its course in the mill. Therefore a Model Predictive Control (MPC) in the finishing mill as well as in the cooling section has to be implemented. This control takes into account the actual incoming temperature course and uses the best available actuator (inter-stand cooling or speed change) selected by an online optimization to achieve the minimum deviation over the whole strip at the exit of the mill or an intermediate target.

\subsection{Crown and Flatness Control}

Special work-roll contour together with Roll Shifting and Bending for strip profile and flatness control are used, enabling tighter tolerance values and reduced off-gauge strip lengths. The roll contour itself can be described as a sum of a sinusoidal and a

* Technical contribution to the 51st Rolling Seminar - Processes, Rolled and Coated Products, October $28^{\text {th }}$ to $31^{\text {st }}$, 2014, Foz do Iguaçu, PR, Brazil. 


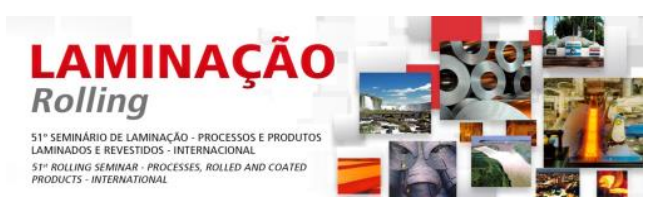

linear function which results in an unloaded roll-gap profile which is always cosineshaped. With the use of a sophisticated profile and flatness model, work rolls are shifted to adjust the roll-gap contour in order to obtain the desired strip profile or to match the roll contour to the crown of the incoming strip.

The principal features and benefits of this solution can be summarized as follows:

- Significantly enhanced profile and flatness control range

- Lower number of work-roll sets in use

- Replacement of all conventional roll crowns with one single contour

- More flexible rolling program and pass schedule design

- Avoidance of all kind of buckles including quarter buckles

\subsection{Microstructure Monitoring (MSM)}

A decisive criterion for the quality of hot-rolled strip is whether it lies within the tolerance range specified by the customer for tensile and yield strength. To document this quality, the rolling mill operator has traditionally been forced to subject samples taken from ongoing production to an extensive - and expensive - series of tests. This testing not only slows down production speed but can also provide unreliable results depending on the intervals between the samples.

The solution to overcome these shortcomings, a new Microstructure Monitor system is used, now determines these quality parameters online during the production process, thus reducing the need for costly laboratory measurements and the time needed to conclude those tests. Additionally, the Microstructure Monitor enables process parameters, such as coiling temperature, to be optimized with regard to target mechanical values.

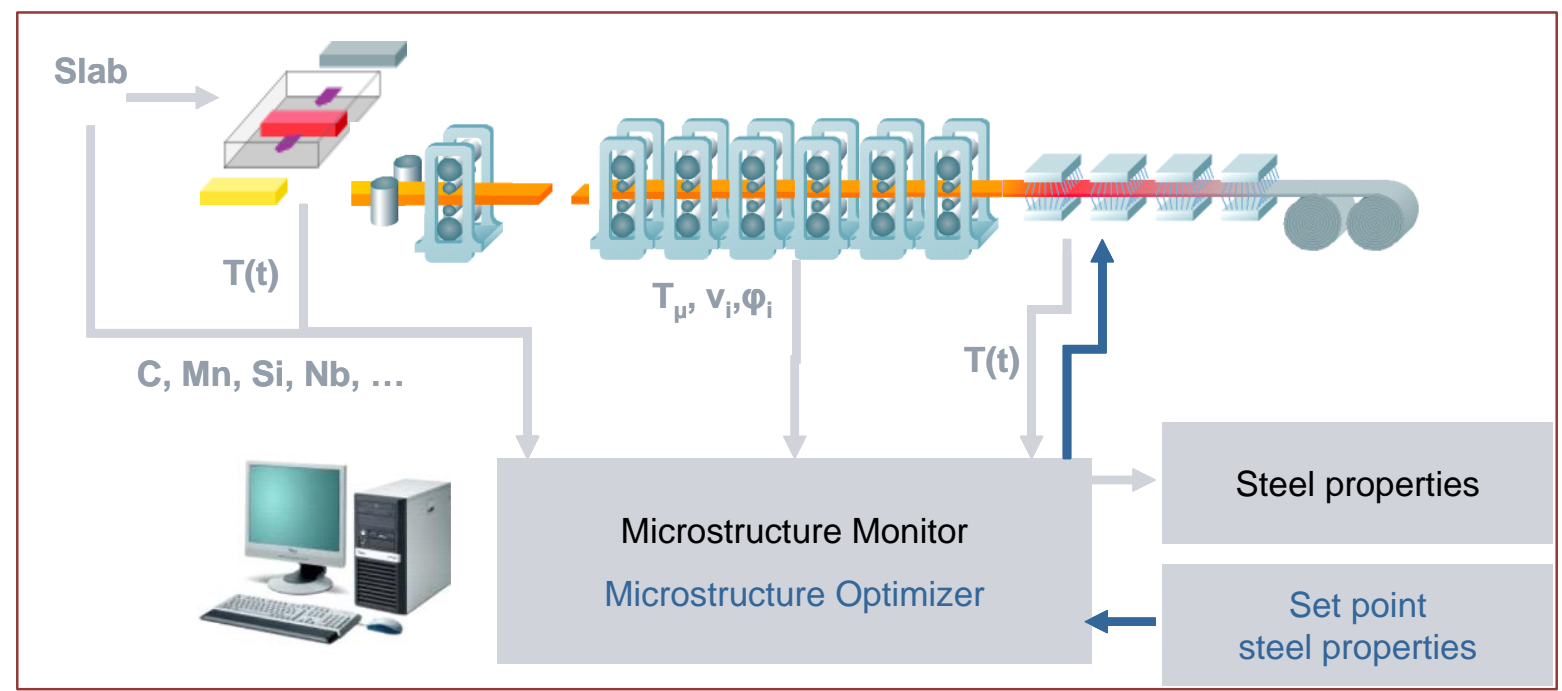

Figure 4: Schematic view of data supply to the MSM and Optimizer

\section{TRENDS IN PROCESS TECHNOLOGIES}

In order to be able to understand the trends in process technologies, it makes sense to take a look at the history of these technologies - in this case, the history of hot strip production.

In a lecture at the Stahl InstitutVDEh, the group of authors describes 5 generations of mill types.

* Technical contribution to the 51st Rolling Seminar - Processes, Rolled and Coated Products, October $28^{\text {th }}$ to $31^{\text {st }}, 2014$, Foz do Iguaçu, PR, Brazil. 


\begin{tabular}{|c|c|c|c|c|c|c|c|c|}
\hline & Time Period & Operating Mode & Raw Material & $\begin{array}{c}\text { Capacity } \\
\text { Mio t/a }\end{array}$ & $\begin{array}{c}\text { Thickness } \\
\mathrm{mm}\end{array}$ & $\begin{array}{l}\text { Number of } \\
\text { Finishing } \\
\text { Stands }\end{array}$ & Automation & \\
\hline Generation I & $1926-1960$ & semi continuous & ingots slabs & $1.5-2.5$ & $>2.5$ & 6 & hand / manual & $\begin{array}{c}\text { A the } \\
\text { Youngstown USA }\end{array}$ \\
\hline Generation II & $1960-1970$ & semi continuous & ingots slabs & $3-4$ & $>1.5$ & 6 & semi automatic & Krupp Dortmund, GER \\
\hline Generation III & $1970-1980$ & fully continuous & $\begin{array}{l}\text { ingot slabs } \\
\text { continuous } \\
\text { casting }\end{array}$ & $5-6$ & $>0.8$ & $7-9$ & semi automatic & $\begin{array}{l}\int_{\text {HSM Chiba No. 3, JP }} \\
\text { TS }\end{array}$ \\
\hline Generation IV & 1980 - & $\begin{array}{l}\text { semi continuous } \\
\text { "three-quarter" } \\
\text { continuous }\end{array}$ & $\begin{array}{l}\text { continuous } \\
\text { casting }\end{array}$ & $5-6$ & $>1.2$ & 7 & fully automatic & $\underset{\text { Shagang HSM, China }}{m a n}$ \\
\hline Generation V & 1990 - & $\begin{array}{c}\text { CSP } \\
\text { ISP } \\
\text { Conroll DSC }\end{array}$ & thin slabs & $1.5-2.5$ & $>0.8$ & $5-7$ & fully automatic & $\frac{42}{y}$ \\
\hline
\end{tabular}

Figure 5: Overview of "5 generations" of hot strip mills

Casting and rolling are still de-coupled in all these 5 generations.

A breakthrough, which will result in a new, sixth generation of hot-strip production, stands on the brink of its industrial implementation. Arvedi and Siemens VAI have built the world's first plant for endless strip production. The casting and rolling are coupled in one production process. The line has been built in Cremona and was commissioned in 2009. Two further ESP line are under construction in China main land since 2013.

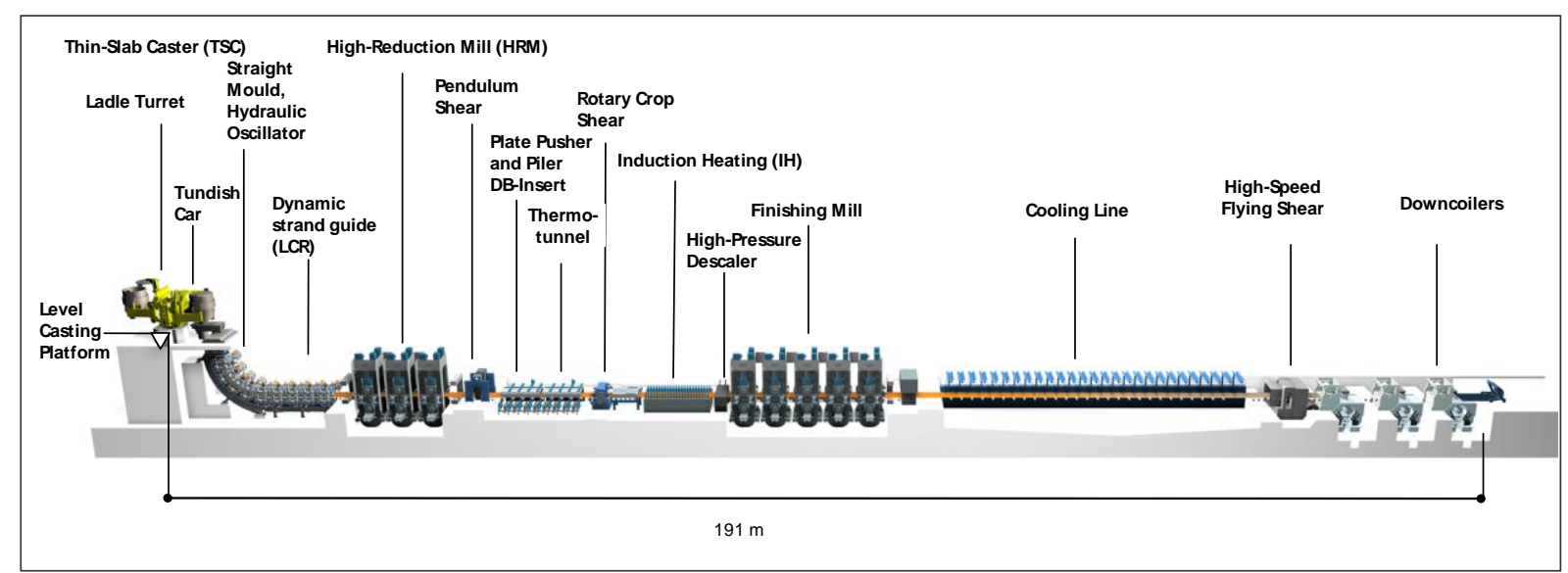

Figure 6: ESP Plant of ARVEDI / Cremona

The total length only amounts to 190 meters and industrial strip thicknesses of less than $1 \mathrm{~mm}$ can be produced. An annual capacity of 2 million tons can be achieved with one strand. The Arvedi ESP concept sets the new benchmark in the area of compound plants.

But, it has to be said clearly, that the most successful continuous strip production is by far the SMS' CSP process, with more than 30 installations worldwide. Italian supplier Danieli has a similar market penetration than the German / Austrian have with their QSP Technology.

* Technical contribution to the 51st Rolling Seminar - Processes, Rolled and Coated Products, October $28^{\text {th }}$ to $31^{\text {st }}$, 2014, Foz do Iguaçu, PR, Brazil. 

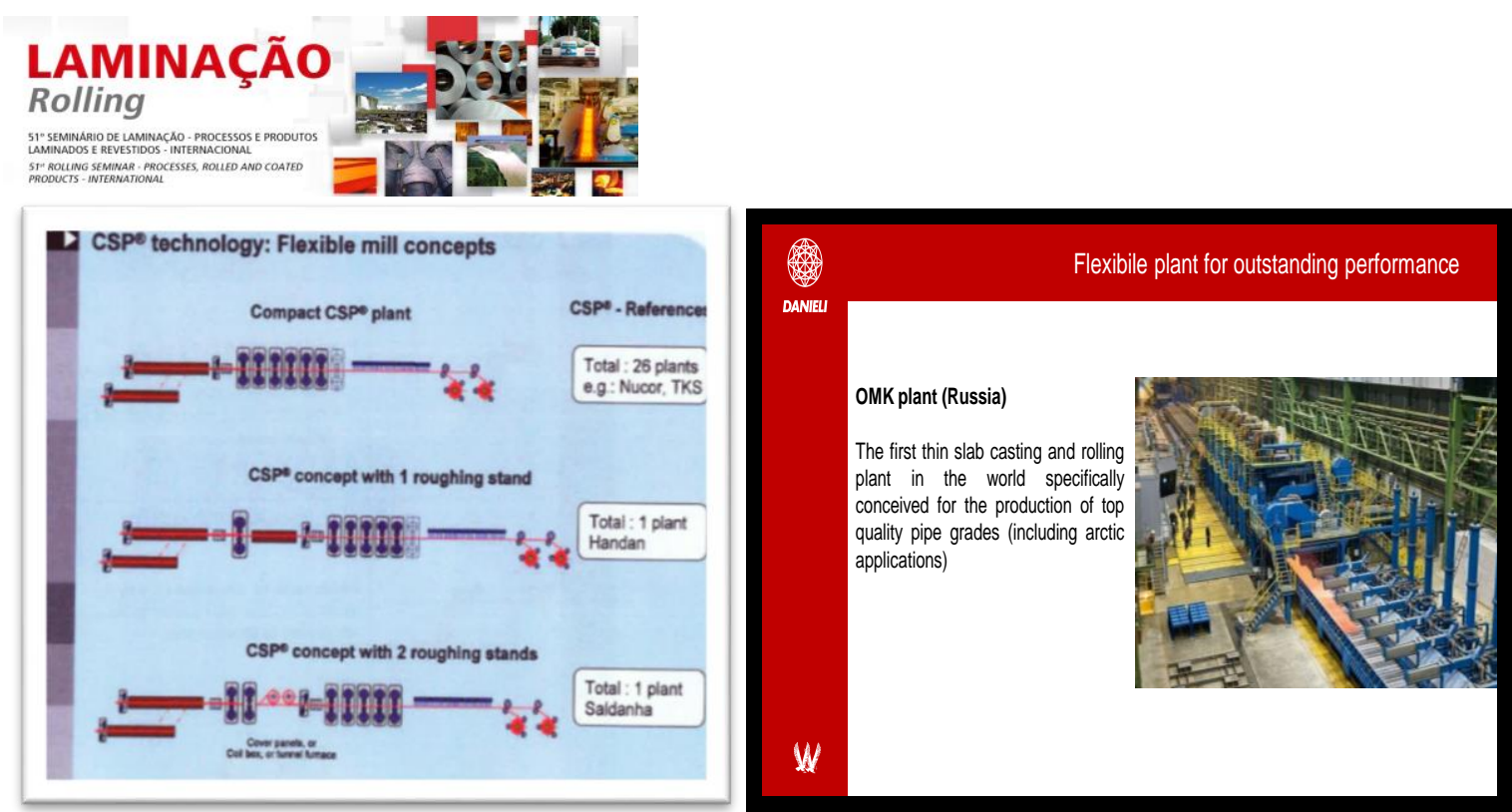

Figure 7 and 8: CSP Plants from SMS, and QSP Plant from Danieli

For new operators that enter in less developed markets or have constraints in qualified and specialized labor and services, the Steckel Mill and the Plate mill in any combination built, is an excellent alternative. Mexican and Brazilian (beside Chinese and even African) operators have recently invested in such mills, which have a very wide range of products. The so called Plate-Steckel-Mill can do in one single stand plates and coils with a very wide range of dimensions.

A combination of both is to be seen in Brasil (Gerdau) where the maximum flexibility can be reached of a combined mill, regarding width and thickness, but also regarding grades of steel. Such a mill can achieve 3 million tons a year (from 2,0 to $150 \mathrm{~mm}$ thick and $900 \mathrm{~mm}$ to $3.800 \mathrm{~mm}$ wide). The three reheating furnaces are positioned in the center of the plant and can thus feed alternatively the plate production (rougher and finisher) as also the Coil production in the Steckel mill.

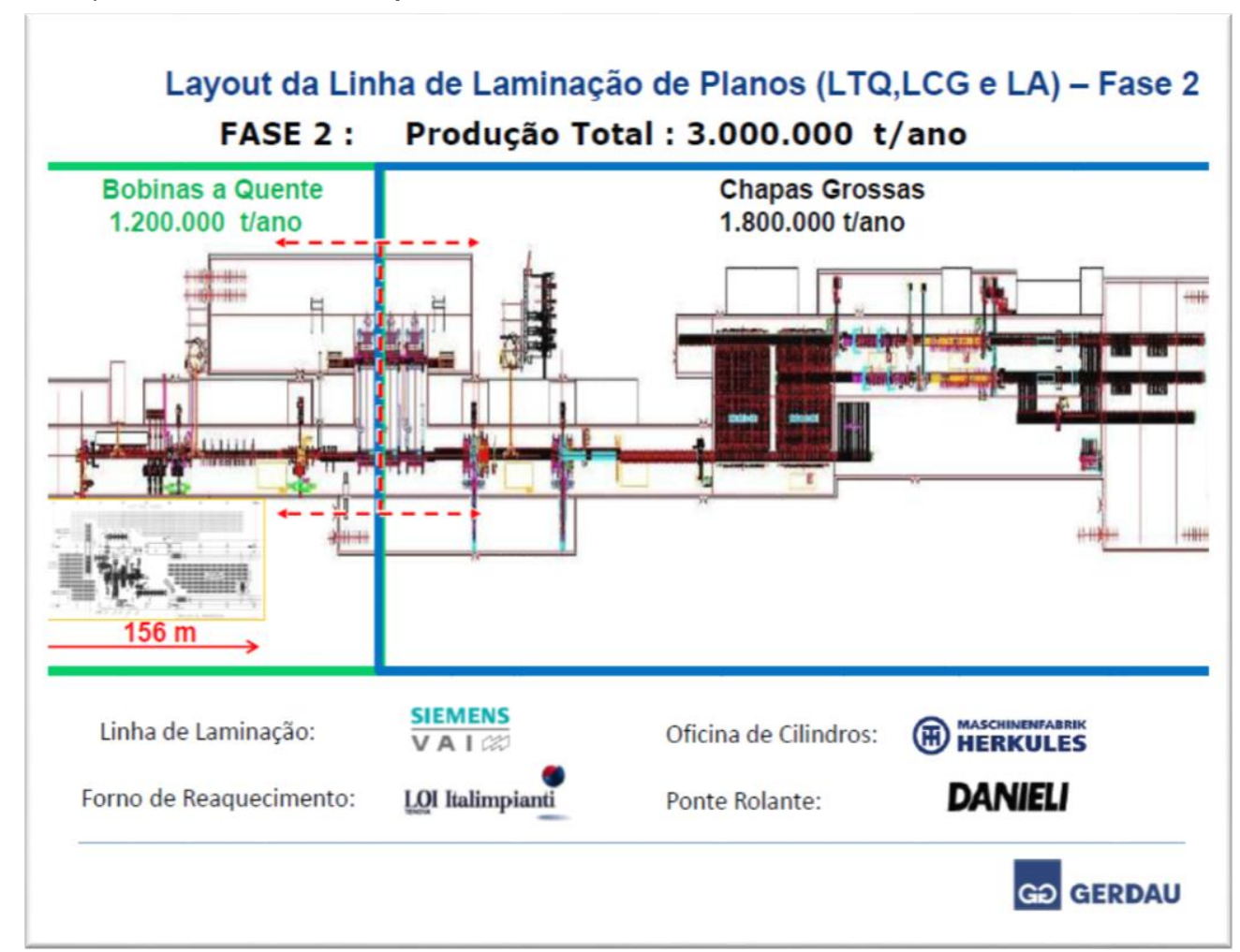

Figure 9: Gerdau's Combination Plate and Steckel Mill (Ouro Branco Site - MG Brasil)

* Technical contribution to the 51st Rolling Seminar - Processes, Rolled and Coated Products, October $28^{\text {th }}$ to $31^{\text {st }}$, 2014, Foz do Iguaçu, PR, Brazil. 


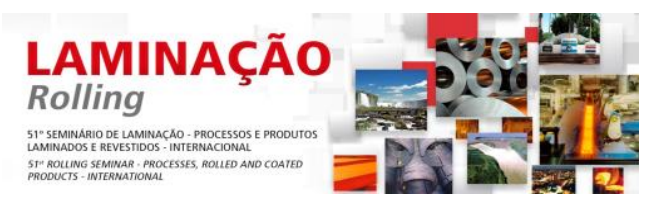

For high productivity mills the classical WSM has still its strong position. The USIMINAS wide strip mill, recently built and very successfully ramped up, is one of the most modern and productive mills on the globe.

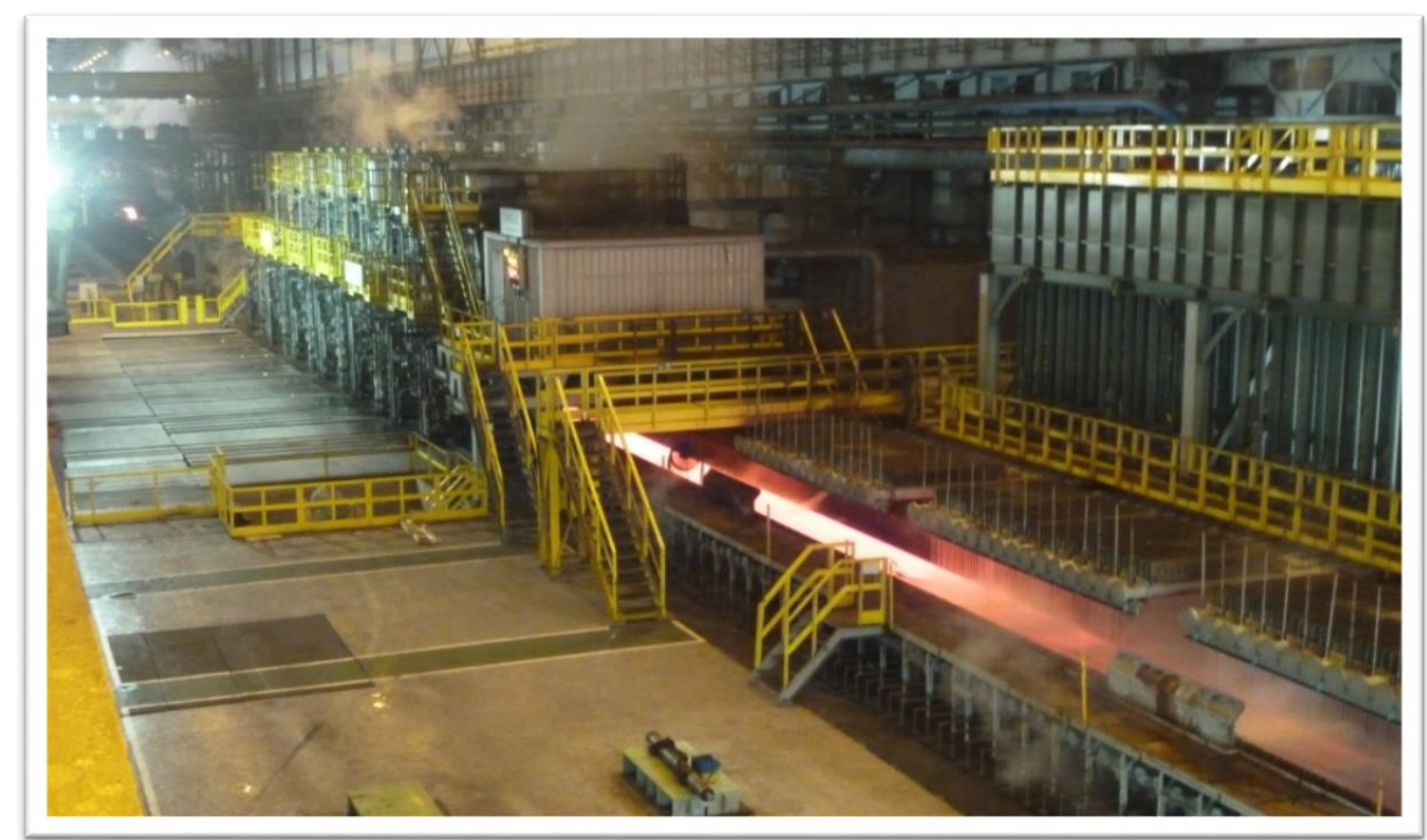

Figure 10: USIMINAS new WSM / Cubatão SP - Brazil

\section{CONCLUSION}

The WSM is still in a very good shape. It is living through its $5^{\text {th }}$ and $6^{\text {th }}$ Generation and new and important developments are on the way. The discontinuous mill will be more and more replaced by continuous mills. Automation systems release the stress on the operators and guarantee the best quality and performance. In the area of rollmaterials a continuous development can be registered. Environmental friendly mills are the "issue of today" and any saved kilowatt-hour helps to get the production costs down.

It is perhaps time to reflect and to put firmly on the map what has been a long and important chapter in the history of technology in the $20^{\text {th }}$ century and to eagerly await what the near and medium future will bring on new features, measures and technologies.

\section{BIBLIOGRAPHY}

1 Ribbon of fire. How Europe adopted and developed the US strip mill technology (19202000). Jonathan Aylen and RuggeroRanieri eds.

2 Maierl J, Giering W. High performance and high tech in hot strip mills - from Solutions to Value. Austria: Siemens VAI.

3 Holy F. Ouro Preto: Rolling Yesterday, Today and the Challenge for Tomorrow [Keynote Speech]. Evraz Group International; October 2013.

* Technical contribution to the 51st Rolling Seminar - Processes, Rolled and Coated Products, October $28^{\text {th }}$ to $31^{\text {st }}$, 2014, Foz do Iguaçu, PR, Brazil. 